\title{
Ultralow friction polymer composites incorporated with mono- dispersed oil microcapsules
}

\author{
Lin ZHANG ${ }^{1}$, Guoxin XIE ${ }^{1, *}$, Shuai WU ${ }^{1}$, Shiguang PENG $^{1}$, Xiaoqing ZHANG ${ }^{2}$, Dan GUO ${ }^{1}$, Shizhu WEN ${ }^{1}$, \\ Jianbin LUO ${ }^{1, *}$ \\ ${ }^{1}$ State Key Laboratory of Tribology, Department of Mechanical Engineering, Tsinghua University, Beijing 100084, China \\ ${ }^{2}$ School of Materials Science and Mechanical Engineering, Beijing Technology and Business University, Beijing 100048, China \\ Received: 15 April 2019 / Revised: 18 June 2019 / Accepted: 01 July 2019 \\ (C) The author(s) 2019.
}

\begin{abstract}
Ultralow friction polymer composites were prepared by adding oil-loaded microcapsules into epoxy (EP) resin. Mono-dispersed polystyrene (PS)/poly alpha olefin (PAO) microcapsules with a diameter of $\sim 2 \mu \mathrm{m}$ and a shell thickness of $\sim 30 \mathrm{~nm}$ were prepared by solvent evaporation method in an oil-in-water emulsion. The lubrication behaviors of the EP resin composites with oil-loaded microcapsules have been investigated under different loads and sliding speeds. As compared with the pure EP resin, the friction coefficient of the composite could be reduced to $4 \%$ (from 0.71 to 0.028 ) and the wear rate could be decreased up to two orders of magnitude. It was demonstrated that the released PAO oil from the microcapsules during the friction process produced a boundary lubricating film, which could prevent the direct contact of two rubbing surfaces, and thus leading to an extremely low friction coefficient and wear rate. Moreover, the composites with microcapsules could achieve comparable lubrication properties to the case under the external lubrication condition, while the former case could effectively minimize the lubricant leakage and improve the lubrication efficiency.
\end{abstract}

Keywords: polymer composite; microcapsules; solvent evaporation; ultralow friction; boundary lubrication

\section{Introduction}

In recent years, microcontainers, e.g., hollow microspheres, microcapsules, porous microspheres, and metal-organic frameworks (MOFs), with the ability to carry versatile core materials have attracted great interest for their variety of applications [1-6]. Representatively, the microcontainers encapsulated liquids can be employed to develop a new family of selflubricating materials, because traditional external lubrication that lubricants are directly added into the interface of two rubbing surfaces could have some limitations under certain conditions. As compared with external lubrication, the release of liquid lubricants from microcontainers to the interface occurs when triggered by the friction processes (load or temperature), which could prevent lubricant leakage, and thus increasing the durability of the effective lubrication process [7-10].

Recently, epoxy (EP) resin composites incorporated with MOFs microcontainers have been prepared and the improved lubricating performance of the composites was associated with the lubricating film produced by the chemical reaction between the released oleylamine from the capsules and the matrix [5]. Another type of wear-resistant material was prepared by adding microcapsules (hexamethylene diisocyanate (HDI) as the core and acacia gum as the shell material) into the epoxy resin matrix and the characterization results suggested the HDI reacted with the water vapor in the environment to form polyurea, effectively improving the wear resistance of the material [11]. The formation of cavities after the rupture of microcapsules could trap wear debris, which could consequently decrease

* Corresponding authors: Guoxin XIE; E-mail: xgx2014@tsinghua.edu.cn; Jianbin LUO, E-mail: luojb@tsinghua.edu.cn 
the friction coefficient and the wear rate of the composite [12-14]. Microcapsules containing liquid lubricants were also prepared as reservoirs in thermally sprayed coatings with lubrication performances. The coatings containing thick wall microcapsules showed a better thermal input resistance, and nevertheless the microcapsules with the thick wall contained less liquid lubricant, resulting in less obvious enhancement of the lubricating performance of the coating [15]. In addition, a number of studies demonstrated that the increased content of microcapsules or the incorporation of larger microcapsules would optimize the lubrication behaviors of the microcapsule-containing composites due to the larger amount of lubricant released from the ruptured microcapsules during the friction process [16-20]. Nevertheless, it was suggested that the incorporation of more or larger microcapsules would degrade the mechanical properties [21-25]. Furthermore, most of the microcapsules with liquid lubricants inside reported in available literatures were relatively large (usually tens to hundreds of $\mu \mathrm{m}$ in diameter) or poorly dispersed [20,26-28], giving rise to a negative effect on the comprehensive properties of the composites.

The microstructures of microcapsules depend largely on the preparation process technology, and the solvent evaporation method was considered as one of the commonly used processes for synthesizing microspheres in oil-in-water $(\mathrm{O} / \mathrm{W})$ systems $[29,30]$. Parameters including the impeller speed, the surfactant concentration, and the viscosity of the organic phase, etc., strongly influence the size of the microspheres [31-33]. The average size of microcapsules generally decreases with the increasing stirring speed, owing to the fact that the stronger shear force and the increased turbulence facilitate the formation of smaller emulsion droplets [33]. The reduction in the viscosity of the emulsion could also improve the mixing efficiency, and thus enabling the formation of very small diameter $(\sim 1 \mu \mathrm{m})$ droplets [32]. In addition, the high surfactant concentration increases the diffusion rate of the stabilizer molecules at the droplet-aqueous phase interface in the emulsion, giving rise to a large number of stabilizer molecules adsorbed on the droplet surfaces, improving the formation of smaller emulsion droplets by preventing droplets from coalescence [31, 34].
In the present study, an optimized solvent evaporation technique was adopted to prepare small $(\sim 2 \mu \mathrm{m}$ in diameter) and mono-dispersed microcapsules. The synthesized microcapsules were incorporated into the epoxy (EP) resin matrices and the lubrication behaviors of the prepared composites were investigated systematically on the basis of macroscopic ball-ondisc friction tests. Moreover, the lubrication properties of the cases where lubricants were directly added into the interface between the composite surface and the counterface were tested as control experiments. Multiple techniques, e.g., scanning electron microscopy (SEM), transmission electron microscopy (TEM), and thermogravimetry (TG) were employed for characterizing the microstructures, as well as the thermal, the mechanical, and the lubrication properties of samples. To further extend the application of the strategy proposed in this work, a series of small and mono-dispersed microcapsules were also successfully synthesized with the same method, and more details are given in the Electronic Supplementary Material (ESM).

\section{Experimental}

\subsection{Materials}

Lubricant oil PAO6 was supplied by Guangzhou Qijie Chemical Technology Co., Ltd. (China). PS, dichloromethane (DCM, >99.5 wt.\%), polyvinyl alcohol $($ PVA) (degree of polymerization $=1750 \pm 50$ ), and Arabia gum were purchased from Beijing Lanyi Chemical Reagents Co., Ltd. (China). The epoxy resin and the curing agent were obtained from the Struers International Trade Co., Ltd. (Shanghai, China). All materials were used as received without any further purification.

\subsection{Synthesis of PS microcapsules containing PAO oil}

PAO-loaded PS microcapsules were prepared by the solvent evaporation method and the schematic diagram was shown in Fig. 1. PAO (4 g) and PS (2 g) were mixed with $50 \mathrm{~mL} \mathrm{DCM}$ with magnetic stirring for a homogeneous solution. Subsequently, the mixture solution was added to a mixed solution $(200 \mathrm{~mL})$ of 


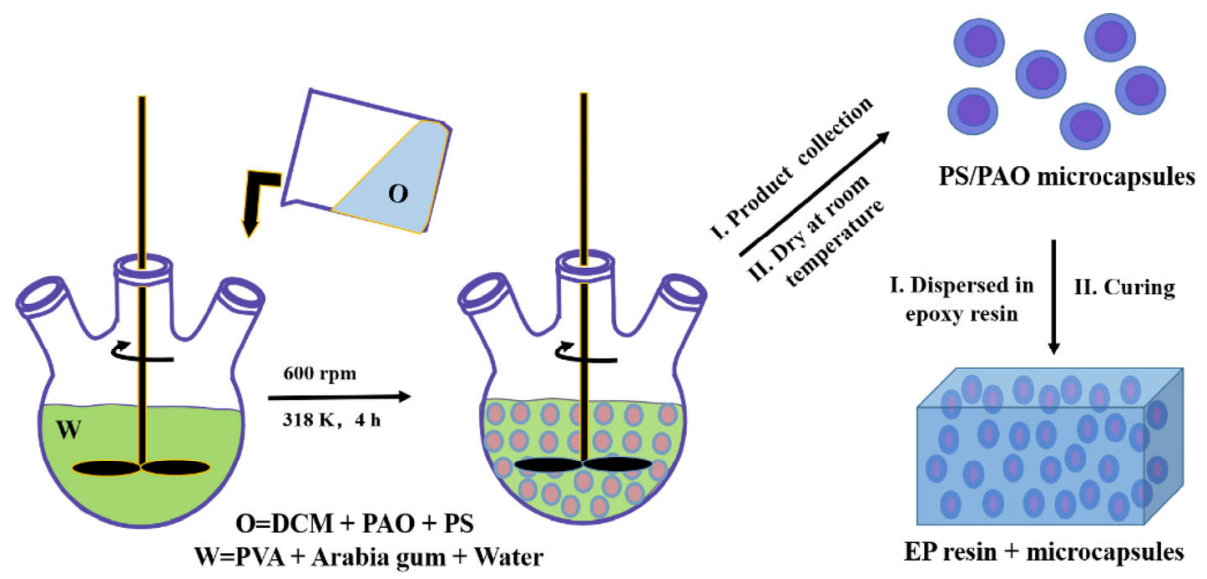

Fig. 1 Schematic diagram of synthesizing microcapsules and preparing epoxy-based composites.

$0.1 \mathrm{wt} . \%$ Arabia gum and $0.5 \mathrm{wt} . \%$ PVA with mechanical stirring at $600 \mathrm{rpm}$. After reacting for $4 \mathrm{~h}$ at $318 \mathrm{~K}$, the DCM evaporated completely and PS microcapsules containing the PAO oil were obtained. The synthesized microcapsules were collected after filtration, repeated rinse with deionized water, and finally being dried at room temperature for $24 \mathrm{~h}$.

\subsection{Preparation of epoxy-based composites}

The synthesized microcapsules were incorporated into the epoxy matrices with different mass fraction for investigating the effect of the microcapsule concentration on the lubrication properties of the epoxybased composites. As shown in Fig. 1, microcapsules of different mass fractions were added into $9 \mathrm{~g} \mathrm{EP}$ liquid under stirring at room temperature for $20 \mathrm{~min}$ to form a good suspension. Then, $3 \mathrm{~g}$ curing agent was added into the above solution under stirring for $10 \mathrm{~min}$ and poured into a rubber mold after the removal of the bubbles in a vacuum drying oven. All the specimens were cured at room temperature for $24 \mathrm{~h}$, producing a series of epoxy-based composites with microcapsules of different mass fractions (5 wt.\%, $10 \mathrm{wt} . \%, 15$ wt. $\%$, and 25 wt. $\%$ ).

\subsection{Frictional tests of the epoxy-based composites}

Frictional tests of pure EP resin and its composites with microcapsules were carried out with a universal microtribometer (UMT-3, CETR, USA) using the ballon-disk mode. GCr45 bearing steel ball of $\Phi 4.68 \mathrm{~mm}$ with a surface roughness of $5 \mathrm{~nm}$ (as provided by the supplier) was used as a counterface material. The ball was thoroughly cleaned with alcohol before each test. As control experiments, the lubrication properties of the cases where lubricants were directly added into the interface between the composite surface and the ball surface were also analyzed under the same experimental conditions. The reciprocating friction stroke was $4 \mathrm{~mm}$ and tests were conducted at normal loads of 3,6 , and $12 \mathrm{~N}$, and the average sliding speeds were 8,16 , and $32 \mathrm{~mm} / \mathrm{s}$.

\subsection{Characterizations of the microcapsules and the epoxy-based composites}

The thermal stability and the core content of the microcapsules containing PAO oil were evaluated using TG analysis from 298 to $873 \mathrm{~K}$ at a heating rate of $10 \mathrm{~K} / \mathrm{min}$ under nitrogen atmosphere. The size distribution of microcapsules was determined by Zetasizer Nano ZSN nanoparticle size analyzer. The morphologies of the microcapsules and the wear tracks of the steel balls sliding against the pure EP resin and the composites with microcapsules were observed by SEM. The shell thickness of the microcapsule was measured by TEM. The mechanical properties (compressive strength and microhardness) of samples were tested by using a universal testing machine and a nanohardness tester. The wear rate and the roughness of the worn composite were measured by three-dimensional white light interference surface topography device (ZYGO Nex View). X-ray photoelectron spectrometry (XPS) analyses were adopted to analyze the electronic states of elements on the transfer films from the composite surface to the steel ball surface. 


\section{Results and discussion}

As shown in Fig. 2(a), monodipersed spherical PS/ PAO microcapsules with the diameter of $\sim 2 \mu \mathrm{m}$ were synthesized by the solvent evaporation method. Various factors such as the surfactant type and concentration, the stirring rate, and the volume of the dispersed phase could influence the synthesis process of microcapsules [30,31]. A mechanical stirring of $600 \mathrm{rpm}$ was efficient and enabled the formation of very small droplets $(\sim 1 \mu \mathrm{m}$ in diameter $)$ at a low emulsion viscosity owing to the large volume of the dispersed phase [32]. Nevertheless, the rapid precipitation of polymer shell could lead to the formation of large microcapsules [32]. When Arabia gum was used as the emulsifier, the hydrophilic polysaccharides on the molecule could form a viscous adsorption layer at the liquid-liquid interface [35]. On the one hand, the adsorbed layer can stabilize the formation of oil droplets in aqueous solutions, and thus minimizing the droplet coalescence. On the other hand, the viscous adsorption layer can reduce the deposition rate of nanoparticles on the surface of microcapsules, effectively avoiding the formation of larger microcapsules owing to too fast precipitation of shell particles. In addition, the synergistic adsorption of different emulsifier molecules at the interface is more effective than that in a single surfactant system in reducing interfacial tension. It was deduced that the larger concentration of the dispersed phase, the co-emulsification of polyvinyl alcohol and Arabia gum mainly promote the formation of smaller monodisperse microcapsules in the present study. Monodispersed filler microparticles are beneficial to achieve good dispersion in composites and eventually to improve the homogeneity of the composites [36-38]. The magnified image of a microcapsule (Fig. 2(b)) suggested that the surface of the microcapsule was smooth and compact without obvious defects and holes, which could effectively improve the stability of the microcapsules. TEM characterizations were employed for obtaining the microstructural information of the microcapsules, and the shell thickness of the microcapsule was $\sim 30 \mathrm{~nm}$, as shown in Fig. 2(c). The thermal stability of the microcapsules, the pure PAO oil, and the PS were analyzed, and the results are shown in Fig. 2(d). In the case of the microcapsules, two main weightless steps at $457 \mathrm{~K}$ and $663 \mathrm{~K}$ were observed from the TG profile, which were clearly assignable to the PAO oil and the PS shell decomposition, respectively. The calculated encapsulation capacity of the microcapsule was about 56 wt.\%.
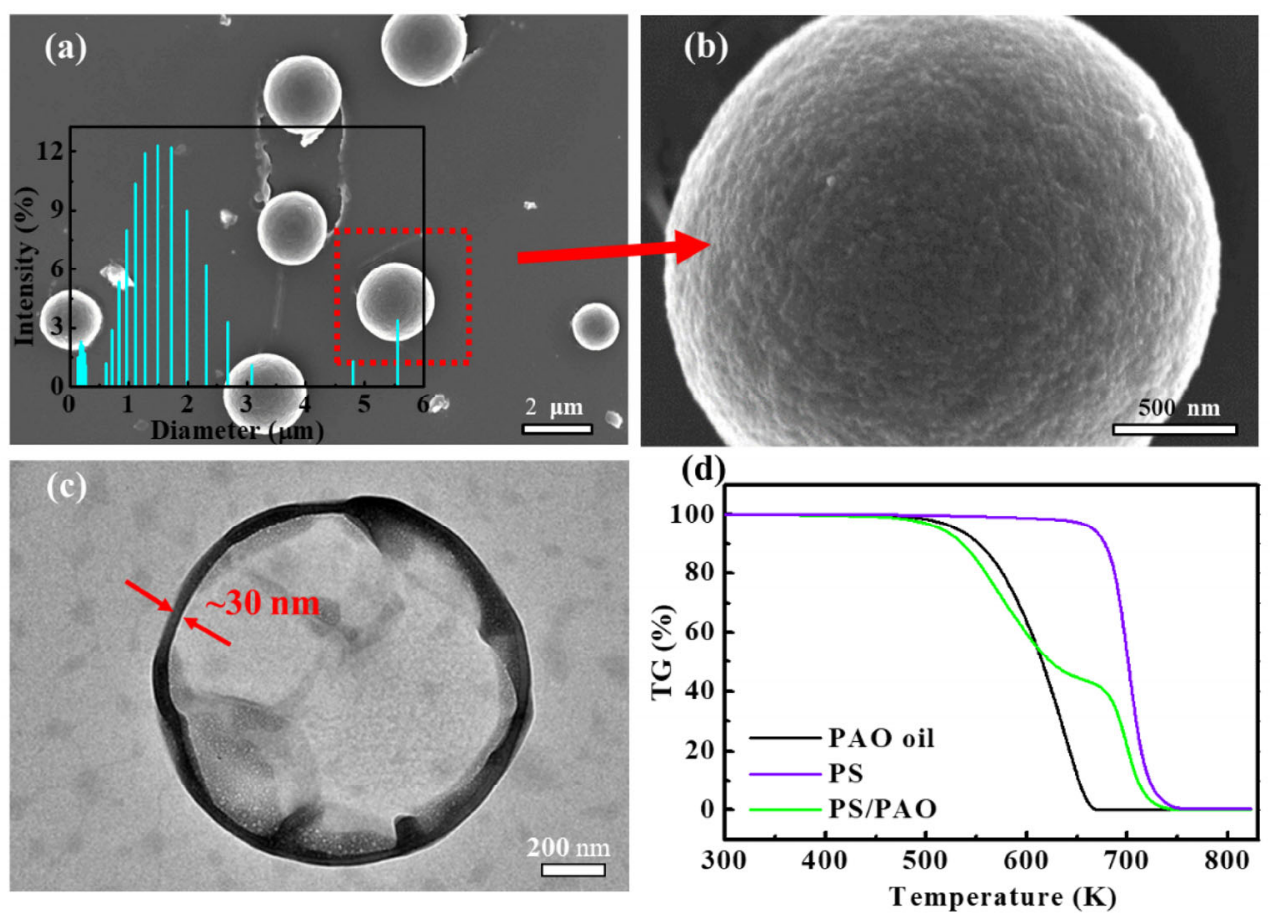

Fig. 2 (a) and (b) SEM images of size distributions, (c) TEM image of PS/PAO microcapsules, and (d) TG curves of the samples. 
Figure 3 presents the compressive strengths and the microhardnesses of the pure EP resin and the composites with different microcapsule contents. The compressive strength and microhardness of the pure EP resin matrix were about $83.5 \mathrm{MPa}$ and $18.7 \mathrm{HV} \mathrm{0.1,}$ respectively. The increased content of microcapsules in the EP resin composites from 5 to $25 \mathrm{wt} . \%$ decreased the compressive strength from 72.1 to $41.1 \mathrm{MPa}$, and the microhardness from 17.6 to $8.2 \mathrm{HV} 0.1$, owing to the increased liquid lubricant in the composite [18, 22].

The lubrication properties of the EP resin and the composites with microcapsules were investigated at different sliding speeds under 3 N. Figure 4 presents the relationship between the friction coefficients of the composites and the microcapsule contents under different sliding speeds. As shown in Figs. 4(a) and 4(c), when the sliding speed was $8 \mathrm{~mm} / \mathrm{s}$, the friction coefficient of the pure epoxy resin was relatively low in the beginning, and then it increased to 0.57 gradually. After the incorporation of microcapsules, the lubrication performance of the composite was greatly improved and the friction coefficient drastically decreased from 0.57 to 0.10 . As for the composite with $15 \mathrm{wt} \%$ microcapsules, the friction coefficient was as low as 0.06. When the microcapsule content was further increased to $25 \mathrm{wt} . \%$, the lubricating property of the microcapsules decreased slightly and the friction coefficient increased to 0.07 . It is inferred that, the rupture of microcapsules in the friction process followed by the lubricant flowing out, resulted in the formation of a lubricant film at the interface [33, 34]. Nevertheless, excessive microcapsules might cause agglomeration in the composite, and poor dispersion of microcapsules would inevitably lead to inefficient lubrication at the interface between two rubbing surfaces. For comparison, the lubrication properties of the PAO oil were carried out under the external lubrication condition where PAO oil was directly added into the interface. As shown in Figs. 4(a) and 4(c), the friction coefficient of the EP resin decreased to 0.07 after adding $2 \mu \mathrm{L}$ PAO oil into the interface, presenting an excellent lubrication performance. The lubrication properties of the composites with different microcapsule contents were further investigated by increasing the sliding speed. As shown in Figs. 4(b) and $4(\mathrm{c})$, the general variation trend of the microcapsule effect on the lubricating properties of composites at the sliding speed of $16 \mathrm{~mm} / \mathrm{s}$ was consistent with that of $8 \mathrm{~mm} / \mathrm{s}$. The friction coefficients of the composites at $16 \mathrm{~mm} / \mathrm{s}$ were lower than those at $8 \mathrm{~mm} / \mathrm{s}$, owing to the fact that the higher sliding speed was more conducive to the formation of a uniform and stable lubricant film at the friction interface. In summary, the above results indicated that the composites with microcapsules could achieve comparable lubrication properties to the case under the external lubrication condition, while the former case could effectively minimize the lubricant leakage and improve the lubrication efficiency.

The lubrication properties of the composite with $15 \mathrm{wt} . \%$ microcapsules were further investigated at different loads and sliding speeds. As shown in Fig. 5, the friction coefficient of the composite decreases gradually with the increase of the load and the sliding

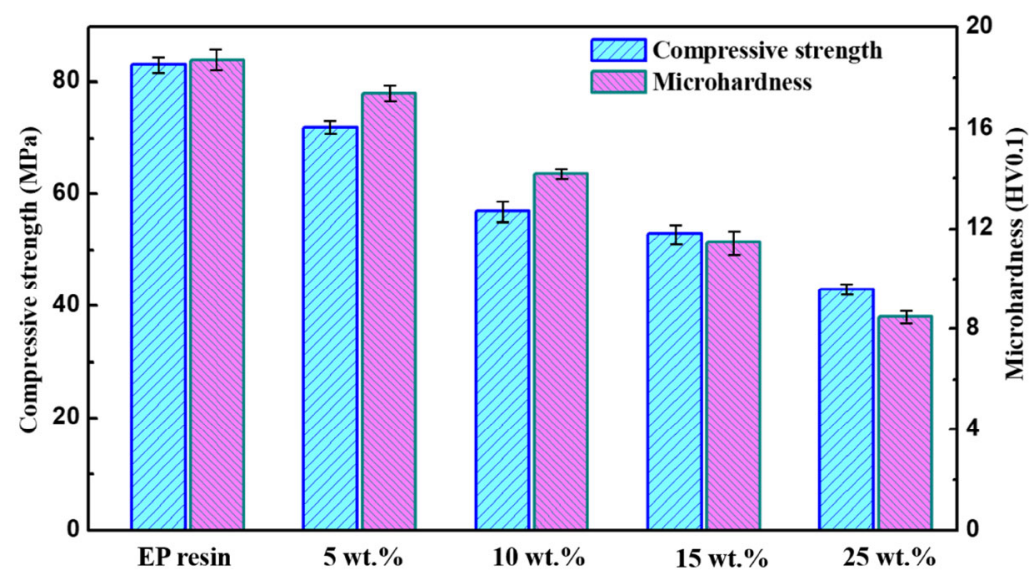

Fig. 3 Compressive strengths and microhardnesses of the pure EP resin and the composite with different microcapsule contents. The error bars indicate the uncertainty of the measured data. 

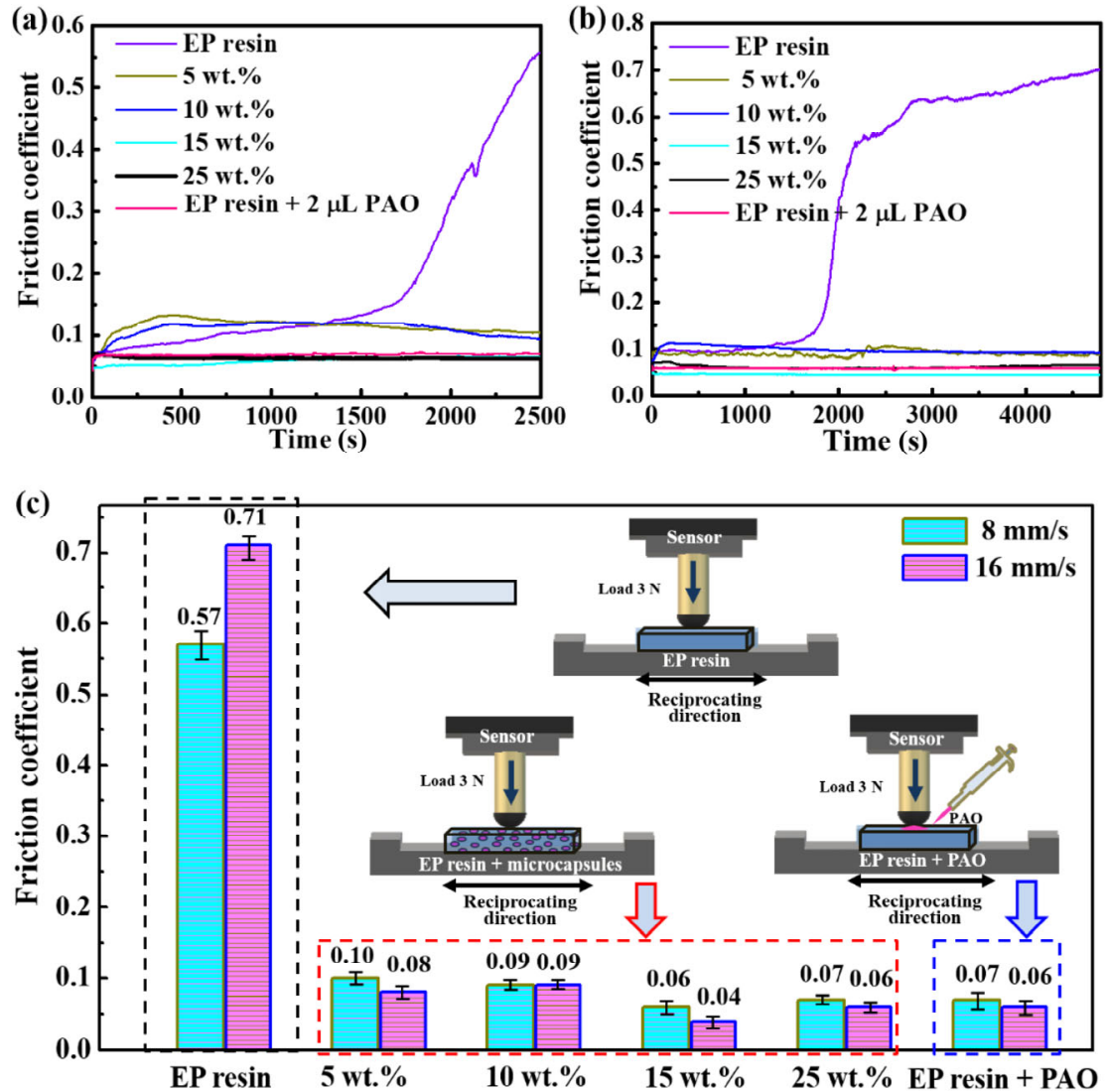

Fig. 4 Friction coefficients of the samples at different sliding speeds under $3 \mathrm{~N}$. (a) and (c): $8 \mathrm{~mm} / \mathrm{s}$, (b) and (c): $16 \mathrm{~mm} / \mathrm{s}$. The error bars indicate the uncertainty of the measured data.
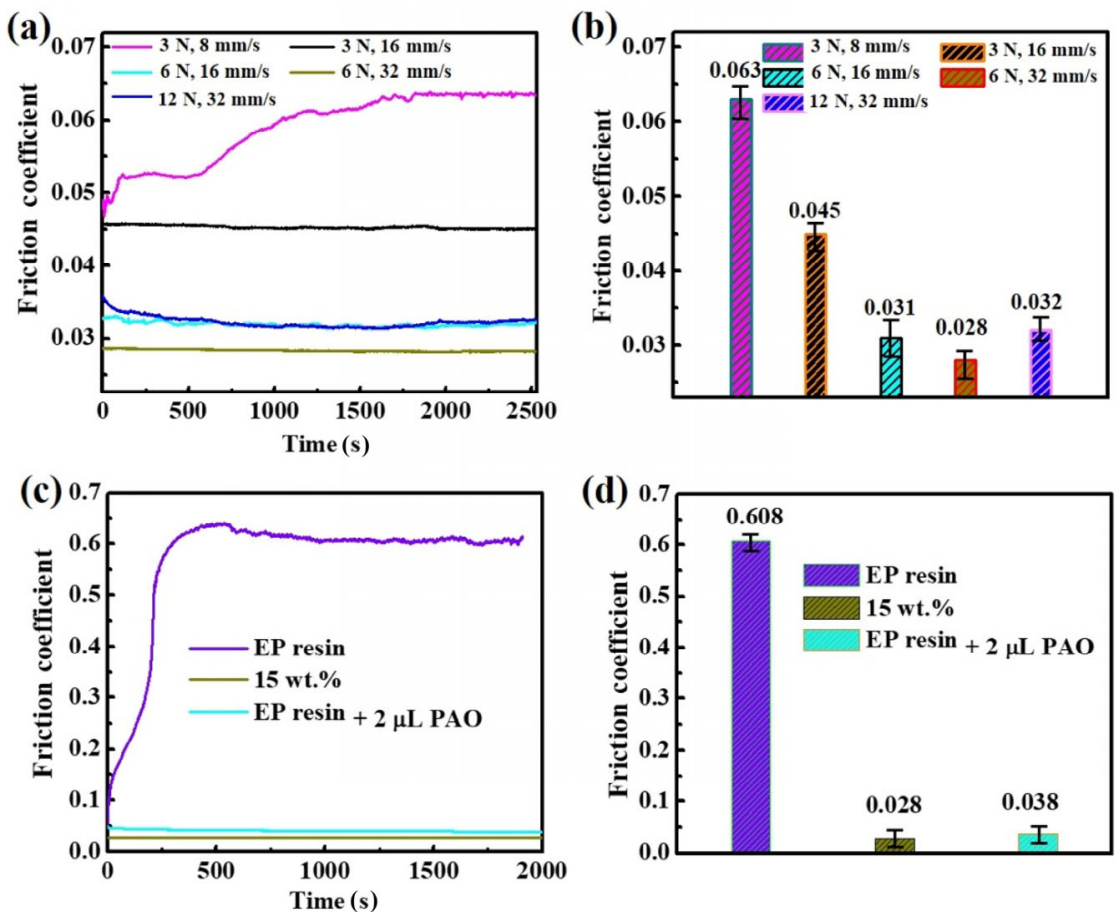

Fig. 5 (a) and (b): friction coefficients of the composites with 15 wt.\% microcapsules at different loads and sliding speeds; (c) and (d): friction coefficients of the EP resin and EP resin $+2 \mu \mathrm{L}$ PAO under $32 \mathrm{~mm} / \mathrm{s}$ and $6 \mathrm{~N}$. The error bars indicate the uncertainty of the measured data. 
speed, and the lowest value reached 0.028 at $6 \mathrm{~N}$ and $32 \mathrm{~mm} / \mathrm{s}$. Presumably, microcapsules were more easily ruptured under large loads with more lubricating oil released. Basically, the lubrication state can be determined by the ratio $(\lambda)$ of the film thickness $(h)$ to the combined surface roughness $(\sigma)(\lambda>3$ : elastohydrodynamic lubrication; $\lambda<1$ : boundary lubrication; $1<\lambda<3$ : mixed lubrication) [39-42]:

$$
\lambda=\frac{h}{\sigma}=\frac{h}{\sqrt{\sigma_{1}^{2}+\sigma_{2}^{2}}},
$$

where $\sigma_{1}\left(\sigma_{1}=123 \mathrm{~nm}\right)$ and $\sigma_{2}\left(\sigma_{2}=82 \mathrm{~nm}\right)$ are the surface roughnesses of the wear spot on the ball surface and the wear scar area on the composite surface, respectively. The $h$ can be theoretically calculated by Hamrock-Dowson formula [43]:

$$
\begin{gathered}
H=3.63 \frac{U^{0.68} G^{0.49}}{W^{0.073}}\left(1-\mathrm{e}^{-0.68 k}\right), \\
H=\frac{h}{R}, U=\frac{\eta v}{E^{\prime} R}, G=\alpha E^{\prime}, W=\frac{F}{E^{\prime} R^{2}},
\end{gathered}
$$

where $R(R=0.0023 \mathrm{~m})$ is the ball radius, $\eta(\eta=0.0242$ Pa.s $)$ is the lubricant viscosity, $v(v=0.032 \mathrm{~m} / \mathrm{s})$ is the sliding speed, $E^{\prime}\left(E^{\prime}=1.16 \times 10^{9} \mathrm{~Pa}\right)$ is the effective elastic modulus, $F(F=6 \mathrm{~N})$ is the normal load, $\alpha(\alpha=$ $\left.1.58 \times 10^{-8} \mathrm{~Pa}^{-1}\right)$ is the viscosity-pressure coefficient, and $k(k=1.03)$ is the ellipticity parameter. According to the given experimental parameters, the calculated $h$ and $\lambda$ are $9.49 \mathrm{~nm}$ and 0.064 , respectively, and thus it can be inferred that the lubrication state was boundary lubrication [40-43]. In this case, it can be reasonable to expect that the thicker lubrication film was established with the increasing sliding speed, giving rise to the reduction of the friction coefficient owing to the decrease of the direct contact ratio of the asperities at the friction interface. Nevertheless, the friction coefficient of the composite increased when the load was increased further to $12 \mathrm{~N}$, and it is inferred that the larger load destroyed the lubricant film at the friction interface. In contrast, the lubrication properties of the EP resin and the PAO under the external lubrication condition (EP resin $+2 \mu \mathrm{L}$ PAO) were also tested under $32 \mathrm{~mm} / \mathrm{s}$ and $6 \mathrm{~N}$, as shown in Figs. 5(c) and $5(\mathrm{~d})$. In contrast to the high friction coefficient (0.608) of the pure epoxy, both the composites with microcapsules and the case under the external lubrication condition achieved ultra-low friction coefficients. It is basically consistent with the reported result in Ref. [44] that the PAO oil could exhibit the excellent lubrication performance (friction coefficient: 0.02 ) under the boundary lubrication condition. As for the composites with microcapsules, lubricating oil appeared at the friction interface in the form of many tiny droplets along with the rupture of microcapsules, which could effectively avoid the drag and energy dissipation caused by lubricating oil spreading in the sliding process under the external lubrication.

The 3D surface morphologies of the wear scars on the surfaces of the pure EP resin and the composites after friction tests and the corresponding wear rates are presented in Fig. 6. As can be seen in Fig. 6(a), the wear scar of the pure epoxy was wide and deep. After adding $5 \mathrm{wt} . \%$ microcapsules, the width and depth of the wear scar decreased significantly, and the wear rate $\left(6.7 \times 10^{-7} \mathrm{~mm}^{3} \cdot(\mathrm{N} \cdot \mathrm{m})^{-1}\right)$ was much smaller, only $0.25 \%$ that of the pure EP resin $\left(2.7 \times 10^{-4} \mathrm{~mm}^{3} \cdot(\mathrm{N} \cdot \mathrm{m})^{-1}\right)$. Nevertheless, as the microcapsule content increased, the wear rate of the composite increased gradually, owing to the reduced mechanical properties of the composite as well as the more vacancies left after the release of the lubricating oil from the microcapsules. To gain more insights into the friction mechanisms, the morphologies and the roughnesses of the worn surfaces were further analyzed. The worn surface of the pure EP resin was very rough, with an average roughness of $744 \mathrm{~nm}$. After adding microcapsules into the matrix, the worn surface became smooth and the roughness was greatly reduced. As for the composite with $15 \mathrm{wt} . \%$ microcapsules, the roughness of the worn surface was the lowest $(82 \mathrm{~nm})$, being conducive to realizing a good lubricating state.

For polymer-on-metal sliding interfaces, there is a natural propensity for the polymer material to be transferred onto the metallic counterface $[45,46]$. The presence of a uniform and thin transfer film is beneficial to the sliding process, because the film protects the relatively soft polymer bulk from the abrasive action of the hard asperities on the metallic surface [47, 48]. The SEM micrographs of the surfaces of the steel balls after sliding against the EP resin and the composites with microcapsules are presented in Fig. 7. The obvious scuffing on the ball surface against the pure EP resin 

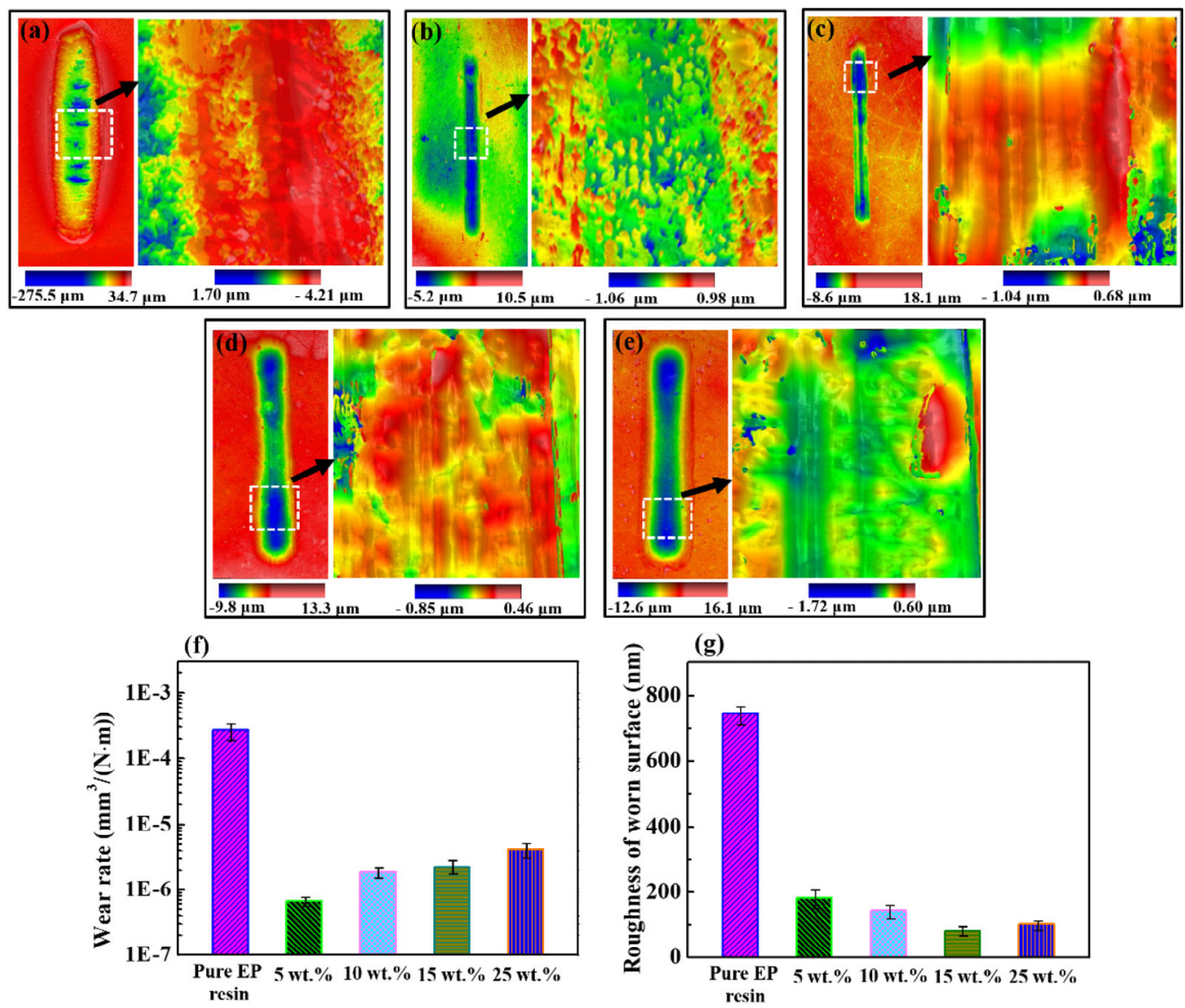

Fig. 6 Surface morphologies of the worn surfaces of the pure EP resin and the composites: (a) the pure EP resin, (b) the composite with 5 wt.\% microcapsules, (c) the composite with 10 wt.\% microcapsules, (d) the composite with 15 wt.\% microcapsules, and (e) the composite with 25 wt.\% microcapsules, (f) the wear rates of the samples, and (g) the worn surface roughnesses of the samples. The error bars indicate the uncertainty of the measured data.
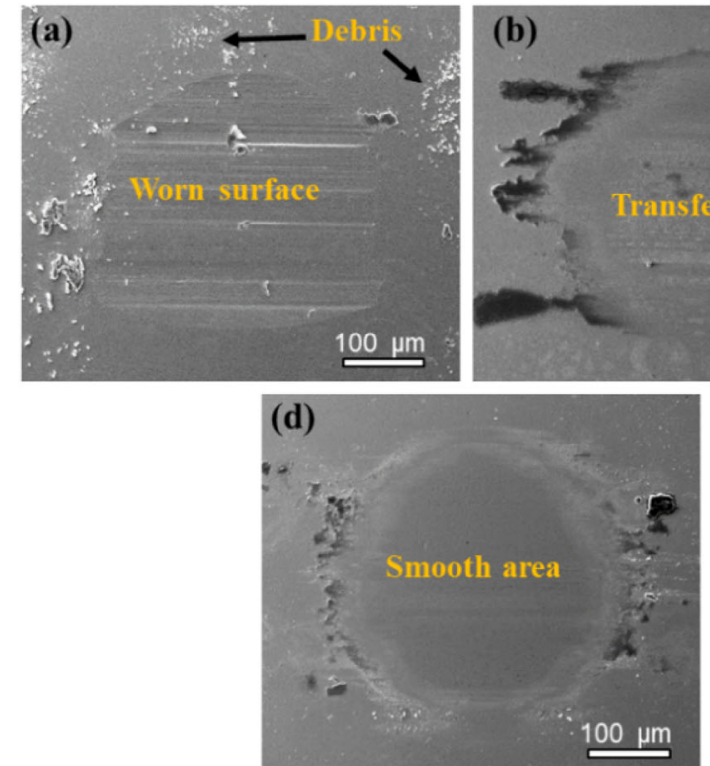
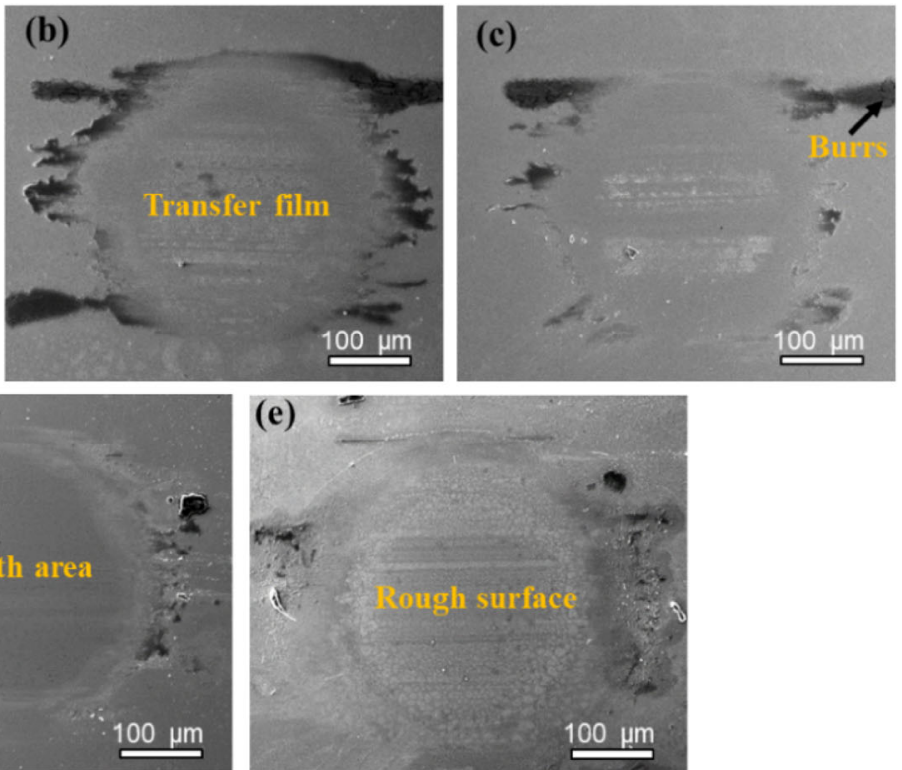

Fig. 7 SEM images of the ball surfaces sliding against different composites: (a) the pure EP resin, (b) the composite with 5 wt.\% microcapsules, (c) the composite with $10 \mathrm{wt} \%$ microcapsules, (d) the composite with $15 \mathrm{wt} \%$ microcapsules, and (e) the composite with 25 wt.\% microcapsules. 
indicated severe plowing of the ball by the resin surface occurred during the friction process. In this case, the transfer film from the resin surface was of poor quality, or no transfer film formed. In contrast, no obvious scuffing was observed on the ball surface against the composite with microcapsules, and it could be ascribed to the tenacious character of the transfer film formed on the ball surface. As shown in Fig. 7(d), the ball surface sliding against the composite with $15 \mathrm{wt} . \%$ microcapsules was relatively smooth. Nevertheless, the surface became rough when the microcapsule content was increased to $25 \mathrm{wt} . \%$ in the composite. After the formation of a smooth, uniform, and tenacious transfer film, the subsequent sliding occurred under the lubrication of the boundary oil film on the composite surface and the transfer film covering the ball surface, and therefore a lower friction coefficient and wear rate was obtained.

XPS analyses of the ball surfaces were performed to verify the surface compositions after friction tests. In the XPS spectra of C1s (Fig. 8(a)), the peaks observed at 284.6 and $286.1 \mathrm{eV}$ were attributed to the carbons in hydrocarbon C-C/C-H and C-O, respectively [49]. After microcapsules were added into the composite, the peak moved towards the low binding energy. In the friction process, the rupture of microcapsules and the flow out of the lubricant to form a lubrication film on the ball surface contained a large number of C-C and $\mathrm{C}-\mathrm{H}$ bonds, resulting in the shift to the low binding energy. As can be seen in the XPS spectra of Fe2 $\mathrm{p}_{3 / 2}$ (Fig. 8(b)), there were obvious characteristic peaks of Fe element, indicating that the transfer film was of poor quality or no transfer film formed. Nevertheless, it was noteworthy that after adding microcapsules in the composite, the characteristic peaks of $\mathrm{Fe} 2 \mathrm{p}_{3 / 2}$ detected on the surface were extremely weak or even disappeared completely when the mass fractions of microcapsules were $10 \mathrm{wt} . \%$ and $15 \mathrm{wt} . \%$. It was inferred that the lubricant flew out of the microcapsule during the friction process and a dense lubricant film formed to cover the ball surface, and thus the characteristic peaks of the Fe element could not be detected.

\section{Conclusions}

Monodispersed PS microcapsules containing the PAO oil were successfully prepared using the solvent evaporation method. The diameter and the shell thickness of microcapsules were approximately 2 and $30 \mathrm{~nm}$, respectively. Self-lubricating composites were also fabricated by incorporating the microcapsules into the EP resin. The lubrication properties of the epoxy composites could be greatly improved by the addition of oil microcapsules. As compared to pure EP resin, the friction coefficient and the wear rate of composites with microcapsules reduced to $4 \%$ and $0.25 \%$, respectively. It was demonstrated that the PAO oil released from the microcapsules during the friction process produced a boundary lubricating film, which could prevent the direct contact between two sliding surfaces, leading to the lower friction coefficient and wear rate. In addition, properly increasing the load and the sliding speed could effectively promote the release of the lubricating oil and form a more uniform lubricant film at the friction interface. The strategy proposed in this work is expected to be a general solution which can be extended to other composites with excellent lubricating performances by adding
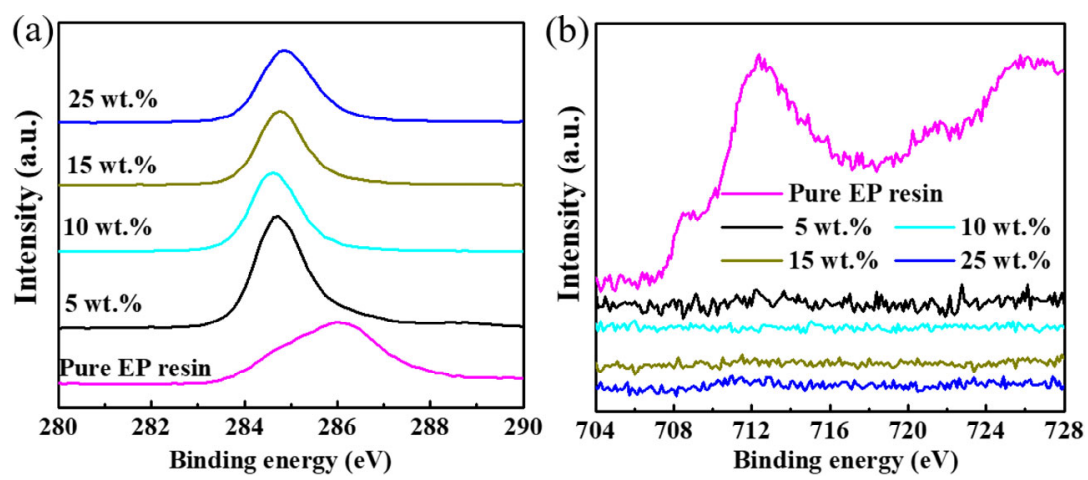

Fig. 8 XPS spectra for the ball surfaces after friction testing: (a) C1s and (b) Fe2 $p_{3 / 2}$. 
microcapsules with different kinds of lubricants into the matrix.

\section{Acknowledgements}

This work was supported by the National Natural Science Foundation of China (Grant Nos. 51822505, 51811530014, and 51605008) and Beijing Natural Science Foundation of China (Grant No. 3182010).

Electronic Supplementary Material: Supplementary material is available in the online version of this article at https://doi.org/ 10.1007/s40544-019-0312-4.

Open Access This article is licensed under a Creative Commons Attribution 4.0 International Li-cense, which permits use, sharing, adaptation, distribution and reproduction in any medium or for-mat, as long as you give appropriate credit to the original author(s) and the source, provide a link to the Creative Commons licence, and indicate if changes were made.

The images or other third party material in this article are included in the article's Creative Commons licence, unless indicated otherwise in a credit line to the material. If material is not in-cluded in the article's Creative Commons licence and your intended use is not permitted by statutory regulation or exceeds the permitted use, you will need to obtain permission directly from the copyright holder.

To view a copy of this licence, visit http:// creativecommons.org/licenses/by/4.0/.

\section{References}

[1] Chen D Z, Qin S Y, Tsui G C P, Tang C Y, Ouyang X, Liu J H, Tang J N, Zuo J D. Fabrication, morphology and thermal properties of octadecylamine-grafted graphene oxide-modified phase-change microcapsules for thermal energy storage. Compos Part B-Eng 157: 239-247 (2019)

[2] Hu Y, Jensen J O, Zhang W, Cleemann L N, Xing W, Bjerrum N J, Li Q F. Hollow spheres of iron carbide nanoparticles encased in graphitic layers as oxygen reduction catalysts. Angew Chem Int Edit 53(14): 3675-3679 (2014)

[3] Es-Haghi H, Mirabedini S M, Imani M, Farnood R R. Mechanical and self-healing properties of a water-based acrylic latex containing linseed oil filled microcapsules: Effect of pre-silanization of microcapsules' shell compound.
Compos Part B-Eng 85: 305-314 (2016)

[4] Naqvi S M, Vedicherla S, Gansau J, Mcintyre T, Doherty M, Buckley C T. Living cell factories-electrosprayed microcapsules and microcarriers for minimally invasive delivery. Adv Mater 28(27): 5662-5671 (2016)

[5] Zhang G L, Xie G X, Si L N, Wen S Z, Guo D. Ultralow friction self-lubricating nanocomposites with mesoporous metal-organic frameworks as smart nanocontainers for lubricants. ACS Appl Mater Interfaces 9(43): 38146-38152 (2017)

[6] Li Q, Siddaramaiah, Kim N H, Hui D, Lee J H. Effects of dual component microcapsules of resin and curing agent on the self-healing efficiency of epoxy. Compos Part B-Eng 55: 79-85 (2013)

[7] Li H Y, Cui Y X, Wang H Y, Zhu Y J, Wang B H. Preparation and application of polysulfone microcapsules containing tung oil in self-healing and self-lubricating epoxy coating. Colloid Surface A 518: 181-187 (2017)

[8] Guo Q B, Lau K T, Zheng B F, Rong M Z, Zhang M Q. Imparting ultra-low friction and wear rate to epoxy by the incorporation of microencapsulated lubricant? Macromol Mater Eng 294(1): 20-24 (2009)

[9] Khun N W, Zhang H, Yang J L, Liu E J. Mechanical and tribological properties of epoxy matrix composites modified with microencapsulated mixture of wax lubricant and multiwalled carbon nanotubes. Friction 1(4): 341-349 (2013)

[10] Yang M M, Zhu X T, Ren G N, Men X H, Guo F, Li P L, Zhang Z Z. Tribological behaviors of polyurethane composite coatings filled with ionic liquid core/silica gel shell microcapsules. Tribol Lett 58(1): 9 (2015)

[11] Khun N W, Sun D W, Huang M X, Yang J L, Yue C Y. Wear resistant epoxy composites with diisocyanate-based self-healing functionality. Wear 313(1-2): 19-28 (2014)

[12] Li H Y, Ma Y J, Li Z K, Cui Y X, Wang H Y. Synthesis of novel multilayer composite microcapsules and their application in self-lubricating polymer composites. Compos Sci Technol 164: 120-128 (2018)

[13] Li H Y, Li S, Li Z K, Zhu Y J, Wang H Y. Polysulfone/SiO hybrid shell microcapsules synthesized by the combination of pickering emulsification and the solvent evaporation technique and their application in self-lubricating composites. Langmuir 33(49): 14149-14155 (2017)

[14] Li H Y, Ma Y J, Li Z K, Ji J, Zhu Y J, Wang H Y. High temperature resistant polysulfone/silica double-wall microcapsules and their application in self-lubricating polypropylene. RSC Adv 7(79): 50328-50335 (2017)

[15] Espallargas N, Vitoux L, Armada S. The wear and lubrication performance of liquid-solid self-lubricated coatings. Surf Coat Technol 235: 342-353 (2013) 
[16] Khun N W, Zhang H, Yue C Y, Yang J L. Self-lubricating and wear resistant epoxy composites incorporated with microencapsulated wax. J Appl Mech 81(7): 071004 (2014)

[17] Ma Y J, Li Z K, Wang H Y, Li H Y. Synthesis and optimization of polyurethane microcapsules containing [BMIm] $\mathrm{PF}_{6}$ ionic liquid lubricant. J Colloid Interface Sci 534: 469-479 (2019)

[18] Mu B, Li X, Yang B P, Cui J F, Wang X, Guo J H, Bao X M, Chen L. Tribological behaviors of polyurethane composites containing self-lubricating microcapsules and reinforced by short carbon fibers. J Appl Polym Sci 134(43): 45331 (2017)

[19] Li H Y, Cui Y X, Li Z K, Zhu Y J, Wang H Y. Fabrication of microcapsules containing dual-functional tung oil and properties suitable for self-healing and self-lubricating coatings. Prog Org Coat 115: 164-171 (2018)

[20] Khun N W, Zhang H, Yang J L, Liu E. Tribological performance of silicone composite coatings filled with waxcontaining microcapsules. Wear 296(1-2): 575-582 (2012)

[21] Hu J F, Chen H Q, Zhang Z B. Mechanical properties of melamine formaldehyde microcapsules for self-healing materials. Mater Chem Phys 118(1): 63-70 (2009)

[22] Behzadnasab M, Esfandeh M, Mirabedini S M, ZohuriaanMehr M J, Farnood R R. Preparation and characterization of linseed oil-filled urea-formaldehyde microcapsules and their effect on mechanical properties of an epoxy-based coating. Colloid Surface A 457: 16-26 (2014)

[23] Keller M W, Sottos N R. Mechanical properties of microcapsules used in a self-healing polymer. Exp Mech 46(6): 725-733 (2006)

[24] Yin T, Rong M Z, Zhang M Q, Yang GC. Self-healing epoxy composites-preparation and effect of the healant consisting of microencapsulated epoxy and latent curing agent. Compos Sci Technol 67(2): 201-212 (2007)

[25] Guo Q B, Lau K T, Rong M Z, Zhang M Q. Optimization of tribological and mechanical properties of epoxy through hybrid filling. Wear 269(1-2): 13-20 (2010)

[26] Imani A, Zhang H, Owais M, Zhao J, Chu P F, Yang J L, Zhang Z. Wear and friction of epoxy based nanocomposites with silica nanoparticles and wax-containing microcapsules. Compos Part A 107: 607-615 (2018)

[27] Sun D W, Chong Y B, Chen K, Yang J L. Chemically and thermally stable isocyanate microcapsules having good self-healing and self-lubricating performances. Chem Eng $J$ 346: 289-297 (2018)

[28] Armada S, Schmid R, Equey S, Fagoaga I, Espallargas N. Liquid-solid self-lubricated coatings. $J$ Therm Spray Technol 22(1): 10-17 (2013)

[29] Yang C Y, Tsay S Y, Tsiang R C C. An enhanced process for encapsulating aspirin in ethyl cellulose microcapsules by solvent evaporation in an $\mathrm{O} / \mathrm{W}$ emulsion. J Microencapsulation
17(3): 269-277 (2000)

[30] Ming L, Rouaud O, Poncelet D. Microencapsulation by solvent evaporation: State of the art for process engineering approaches. Int J Pharm 363(1-2): 26-39 (2008)

[31] Couvreur P, Blanco-Prieto M J, Puisieux F, Roques B, Fattal E. Multiple emulsion technology for the design of microspheres containing peptides and oligopeptides. $A d v$ Drug Del Rev 28(1): 85-96 (1997)

[32] Valot P, Baba M, Nedelec J M, Sintes-Zydowicz N. Effects of process parameters on the properties of biocompatible ibuprofen-loaded microcapsules. Int $J$ Pharm 369(1-2): 53-63 (2009)

[33] Freitas S, Merkle H P, Gander B. Microencapsulation by solvent extraction/evaporation: Reviewing the state of the art of microsphere preparation process technology. $J$ Controlled Release 102(2): 313-332 (2005)

[34] Jeffery H, Davis S S, O'Hagan D T. The preparation and characterization of poly(Lactide-Co-Glycolide) microparticles. II. The entrapment of a model protein using a (water-inoil)-in-water emulsion solvent evaporation technique. Pharm Res 10(3): 362-368 (1993)

[35] Dickinson E. Hydrocolloids as emulsifiers and emulsion stabilizers. Food Hydrocolloid 23(6): 1473-1482 (2009)

[36] Sun Y Y, Zhang Z Q, Wong C P. Study on mono-dispersed nano-size silica by surface modification for underfill applications. J Colloid Interface Sci 292(2): 436-444 (2005)

[37] Klapdohr S, Moszner N. New inorganic components for dental filling composites. Monatsh Chem 136(1): 21-45 (2005)

[38] Zhang G, Sebastian R, Burkhart T, Friedrich K. Role of monodispersed nanoparticles on the tribological behavior of conventional epoxy composites filled with carbon fibers and graphite lubricants. Wear 292-293: 176-187 (2012)

[39] Wang W, He Y Y, Zhao J, Mao J, Hu Y, Luo J B. Optimization of groove texture profile to improve hydrodynamic lubrication performance: Theory and experiments. Friction: 1-12 (2018)

[40] Etsion I. Modeling of surface texturing in hydrodynamic lubrication. Friction 1(3): 195-209 (2013)

[41] Wen S Z, Huang P. Principles of Tribology. Hoboken (USA): John Wiley \& Sons, 2012.

[42] Luo J B, Lu X C, Wen S Z. Developments and unsolved problems in nano-lubrication. Prog Nat Sci 11(3): 173-183 (2001)

[43] Hamrock B J, Dowson D. Isothermal elastohydrodynamic lubrication of point contacts: Part III-Fully flooded results. J Lubr Technol 99(2): 264-276 (1977)

[44] Battez A H, Gonzalez R, Viesca J L, Fernández J E, Ferná ndez J M D, Machado A, Chou R, Riba J. CuO, $\mathrm{ZrO}_{2}$ and $\mathrm{ZnO}$ nanoparticles as antiwear additive in oil lubricants. 
Wear 265(3-4): 422-428 (2008)

[45] Abdelbary A, Abouelwafa M N, El Fahham I M. Evaluation and prediction of the effect of load frequency on the wear properties of pre-cracked nylon 66. Friction 2(3): 240-254 (2014)

[46] Li Z X, Ma S H, Zhang G, Wang D A, Zhou F. Soft/hardcoupled amphiphilic polymer nanospheres for water lubrication. ACS Appl Mater Interfaces 10(10): 9178-9187 (2018)

[47] Li S, Duan C J, Li X, Shao M C, Qu C H, Zhang D, Wang

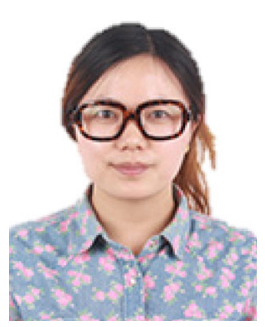

Lin ZHANG. She received her Ph.D. degree at Beijing University of Chemical Technology, in 2017, majoring in chemical engineering and technology. She is currently a post-doctor at the State Key

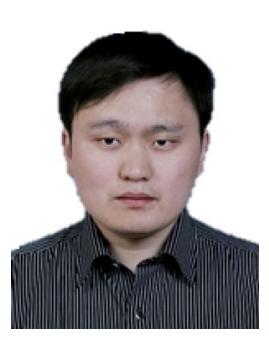

Guoxin XIE. He received his Ph.D. degree at Tsinghua University, China, in 2010, majoring in mechanical engineering. After that, he spent two years at State Key Laboratory of Tribology, Tsinghua University, China for postdoctoral research. From 2012 to 2014, he worked at Royal Institute of Technology, Sweden, for another two-year

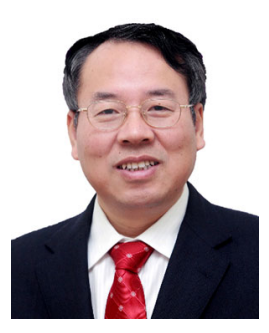

Jianbin LUO. He received his BEng degree from Northeastern University in 1982, and got his MEng degree from Xi'an University of Architecture and Technology in 1988. In 1994, he received his Ph.D. degree from Tsinghua University and then joined the faculty of Tsinghua University. Prof. Jianbin Luo is an academician of the Chinese Academy of Sciences and a Yangtze River Scholar Distinguished Professor
Q H, Wang T M, Zhang X R. The effect of different layered materials on the tribological properties of PTFE composites. Friction (2019) DOI: 10.1007/s40544-019-0276-4 (in Press)

[48] Myshkin N, Kovalev A. Adhesion and surface forces in polymer tribology-A review. Friction 6(2): 143-155 (2018)

[49] Nedelcu I, Piras E, Rossi A, Pasaribu H R. XPS analysis on the influence of water on the evolution of zinc dialkyldithiophosphate-derived reaction layer in lubricated rolling contacts. Surf Interface Anal 44(8): 1219-1224 (2012)

Laboratory of Tribology of Tsinghua University. Dr. Zhang has published 6 papers in international journals indexed by SCI. Her research interests include the self-lubricating polymer composites, self-healing materials, and core-shell materials, etc.

post-doctoral research. Since 2014, he has worked at Tsinghua University as an associate professor. His research interests include intelligent self-lubrication, electric contact lubrication, etc. He has published more than 50 referred papers in international journals. He won several important academic awards, such as Chinese Thousands of Young Talents, the Excellent Doctoral Dissertation Award of China, and Ragnar Holm Plaque from KTH, Sweden.

of Tsinghua University, Beijing, China. He was awarded the STLE International Award (2013), the Chinese National Technology Progress Prize (2008), the Chinese National Natural Science Prize (2001), and the Chinese National Invention Prize (1996). Prof. Luo has been engaged in the research of thin film lubrication and tribology in nanomanufacturing. He has been invited as a keynote or plenary speaker for 20 times on the international conferences. 